\title{
Pacemaking in Dopaminergic Ventral Tegmental Area Neurons: Depolarizing Drive from Background and Voltage-Dependent Sodium Conductances
}

\author{
Zayd M. Khaliq and Bruce P. Bean \\ Department of Neurobiology, Harvard Medical School, Boston, Massachusetts 02115
}

\begin{abstract}
Dopaminergic neurons in the ventral tegmental area (VTA) fire spontaneously in a pacemaker-like manner. We analyzed the ionic currents that drive pacemaking in dopaminergic VTA neurons, studied in mouse brain slices. Pacemaking was not inhibited by blocking hyperpolarization-activated cation current $\left(I_{\mathrm{h}}\right)$ or blocking all calcium current by $\mathrm{Mg}^{2+}$ replacement of $\mathrm{Ca}^{2+}$. Tetrodotoxin (TTX) stopped spontaneous activity and usually resulted in stable resting potentials near $-60 \mathrm{mV}$ to $-55 \mathrm{mV}, 10-15 \mathrm{mV}$ below the action potential threshold. When external sodium was replaced by $N$-methyl-D-glucamine (NMDG) with TTX present, cells hyperpolarized by an average of $-11 \mathrm{mV}$, suggesting a significant resting sodium conductance not sensitive to TTX. Voltage-clamp experiments using slow (10 $\mathrm{mV} / \mathrm{s}$ ) ramps showed a steady-state, steeply voltage-dependent current blocked by TTX that activates near $-60 \mathrm{mV}$, as well as a sodium "background" current with little voltage sensitivity, revealed by NMDG replacement for sodium with TTX present. We quantified these two components of sodium current during the pacemaking trajectory using action potential clamp. The initial phase of depolarization, up to approximately $-55 \mathrm{mV}$, is driven mainly by non-voltage-dependent sodium background current. Above $-55 \mathrm{mV}$, TTX-sensitive voltage-dependent "persistent" Na current helps drive the final phase of depolarization to the spike threshold. Voltage-dependent calcium current is small at all subthreshold voltages. The pacemaking mechanism in VTA neurons differs from that in substantia nigra pars compacta $(\mathrm{SNc})$ neurons, where subthreshold calcium current plays a dominant role. In addition, we found that non-voltagedependent background sodium current is much smaller in SNc neurons than VTA neurons.
\end{abstract}

\section{Introduction}

Midbrain dopamine neurons play a central role in multiple critical brain functions, including cognition, motivation, reward, and regulation of coordinated movements (Nieoullon, 2002; Wise, 2004; Fields et al., 2007; Schultz, 2007). Multiple populations of midbrain dopamine neurons have been identified that differ both in patterns of projection and in electrophysiological function (Cameron et al., 1997; Wolfart et al., 2001; Neuhoff et al., 2002; Koyama et al., 2005; Ford and Williams, 2006; Margolis et al., 2006; Lammel et al., 2008; Liss and Roeper, 2008; Margolis et al., 2008). However, a common element of most dopamine neurons in the midbrain is that even without synaptic stimulation, they fire spontaneously at typical rates of $0.5-5 \mathrm{~Hz}$, usually in a highly rhythmic "pacemaker" fashion (Grace and Bunney, 1984; Johnson and North, 1992; Nedergaard and Greenfield, 1992; Cameron et al., 1997; Neuhoff et al., 2002; Korotkova et al., 2003; Koyama et al., 2005; Margolis et al., 2006).

The mechanism of pacemaking of dopamine neurons in the substantia nigra pars compacta $(\mathrm{SNc})$ has been studied exten-

Received Jan. 10, 2010; revised March 24, 2010; accepted April 15, 2010

This work was supported by the National Institutes of Health (NS36855). Z.M.K. was supported by a United Negro College Fund/Merck Fellowship.

Correspondence should be addressed to Zayd M. Khaliq, Department of Neurobiology, Harvard Medical School, 220 Longwood Avenue, Boston, MA 02115. E-mail: zayd_khaliq@hms.harvard.edu.

DOI:10.1523/JNEUROSCI.0143-10.2010

Copyright $\odot 2010$ the authors $\quad 0270-6474 / 10 / 307401-13 \$ 15.00 / 0$ sively and appears to depend in large part on current flowing through voltage-gated calcium channels (Fujimura and Matsuda, 1989; Grace and Onn, 1989; Harris et al., 1989; Kang and Kitai, 1993a,b; Nedergaard et al., 1993; Mercuri et al., 1994). In particular, dopaminergic SNc neurons possess a component of voltagedependent calcium current that flows at subthreshold voltages and helps drive membrane voltage to spike threshold (Wilson and Callaway, 2000; Chan et al., 2007; Puopolo et al., 2007; Putzier et al., 2009). This mechanism of pacemaking likely produces an unusually large calcium entry that may contribute to the selective death of SNc dopamine neurons in Parkinson's disease (Chan et al., 2007, 2009; Surmeier, 2007), at least in part by calcium-dependent upregulation of cytoplasmic dopamine levels (Mosharov et al., 2009). Interestingly, dopamine neurons in the neighboring ventral tegmental area (VTA) are largely spared in Parkinson's disease (Dauer and Przedborski, 2003; Mosharov et al., 2009), raising the possibility that they use a different mechanism of pacemaking. However, little is known about the mechanism of pacemaking in dopaminergic VTA neurons.

We examined the contribution of various ionic conductances to pacemaking of dopaminergic VTA neurons by combining current-clamp and voltage-clamp recordings to quantify individual currents flowing during the interspike interval. In contrast to SNc dopamine neurons, voltage-dependent calcium current during the interspike interval is small relative to subthreshold TTXsensitive sodium current, which is the largest voltage-gated current during the interspike interval. Another key element in 
pacemaking of VTA neurons is the presence of a non-voltagedependent background sodium conductance, which results in a "resting" potential near $-55 \mathrm{mV}$, only $10-15 \mathrm{mV}$ hyperpolarized to action potential threshold.

\section{Materials and Methods}

Slice preparation and identification of cells. Coronal brain slices containing the ventral tegmental area were prepared from postnatal day 14-30 transgenic mice in which enhanced green fluorescent protein is driven by the tyrosine hydroxylase (TH) promoter [the $\mathrm{Tg}$ (TH-EGFP)1Gsat GENSAT line, obtained from the NIH Mutant Mouse Regional Resource Center]. Animals were anesthetized with isoflurane and decapitated. Their brains were quickly removed and placed into an ice-cold sucrose slicing solution containing $87 \mathrm{~mm} \mathrm{NaCl}, 25 \mathrm{~mm} \mathrm{NaHCO}, 1.25 \mathrm{~mm}$ $\mathrm{NaH}_{2} \mathrm{PO}_{4}, 2.5 \mathrm{~mm} \mathrm{KCl}, 7.5 \mathrm{~mm} \mathrm{MgCl}, 75 \mathrm{~mm}$ sucrose, and $25 \mathrm{~mm}$ glucose, bubbled with $95 / 5 \% \mathrm{O}_{2} / \mathrm{CO}_{2}$. Slices were cut using a vibratome (DTK-1000; DSK, Dosaka) and incubated for $1 \mathrm{~h}$ at $34^{\circ} \mathrm{C}$, first for $30 \mathrm{~min}$ in slicing solution and then for $30 \mathrm{~min}$ in artificial CSF (ACSF) consisting of $125 \mathrm{~mm} \mathrm{NaCl}, 25 \mathrm{~mm} \mathrm{NaHCO}_{3}, 1.25 \mathrm{~mm} \mathrm{NaH}_{2} \mathrm{PO}_{4}, 3.5 \mathrm{~mm} \mathrm{KCl}, 1 \mathrm{~mm}$ $\mathrm{MgCl}_{2}, 2 \mathrm{mM} \mathrm{CaCl}$, and $10 \mathrm{~mm}$ glucose, bubbled with $95 / 5 \% \mathrm{O}_{2} / \mathrm{CO}_{2}$. Slices were then placed into a heated recording chamber $\left(34 \pm 1^{\circ} \mathrm{C}\right)$ and continuously perfused with ACSF at a rate of $3 \mathrm{ml} / \mathrm{min}$ until the recording began. Dopaminergic neurons were identified as GFP-positive neurons using epifluorescence and a CCD camera (MTI) on a Nikon microscope (E600FN). Within the VTA, there are subpopulations of dopaminergic neurons projecting to different target areas, with somewhat different electrophysiological properties (Lammel et al., 2008). We recorded from neurons in the medial half of the VTA, away from the border with the substantia nigra pars compacta. VTA neurons in this area project to the medial shell of the nucleus accumbens, core of the nucleus accumbens, amygdala, and prefrontal cortex.

Electrophysiological recording. Whole-cell current-clamp or voltageclamp recordings were made with a Multiclamp 700B amplifier (Molecular Devices) using borosilicate patch electrodes (1-3 M $\Omega$ ) wrapped with Parafilm to reduce pipette capacitance. Pipette series resistance (typically 4-8 M $\Omega$ ) was compensated by $70-85 \%$ during voltage-clamp experiments and was checked frequently throughout the experiment; data were not used if series resistance changed by $>20 \%$. Current and voltage signals were filtered at $10 \mathrm{kHz}$ and sampled at $20 \mu$ s using a Digidata 1322A data-acquisition interface (Molecular Devices) and pClamp 9 software (Molecular Devices).

Recording solutions. The standard internal solution for whole-cell recordings consisted of $122 \mathrm{~mm} \mathrm{~K}$ methanesulfonate, $9 \mathrm{~mm} \mathrm{NaCl}, 1.8 \mathrm{~mm}$ $\mathrm{MgCl}_{2}$, 4 mм Mg-ATP, 0.3 mм Na-GTP, 14 mm phosphocreatine, 0.45 EGTA, $0.1 \mathrm{CaCl}_{2}$, and 10 HEPES, pH adjusted to $\mathrm{pH} 7.35$ with $\sim 18 \mathrm{~mm}$ $\mathrm{KOH}$. Reported voltages are corrected for a liquid junction potential of $-8 \mathrm{mV}$ between the internal solution and the external solution in which pipette zero voltage was defined in the beginning of the experiment, measured using a flowing $3 \mathrm{~m} \mathrm{KCl}$ electrode as described by Neher (1992).

The standard external solution consisted of $151 \mathrm{~mm} \mathrm{NaCl}, 3.5 \mathrm{~mm} \mathrm{KCl}$, $2 \mathrm{~mm} \mathrm{CaCl}_{2}, 1 \mathrm{~mm} \mathrm{MgCl}_{2}, 10 \mathrm{~mm}$ glucose, and $10 \mathrm{~mm}$ HEPES, pH adjusted to $\mathrm{pH} 7.35$ with $\mathrm{NaOH}$. This solution and all other external solutions contained blockers of fast synaptic transmission: $5 \mu \mathrm{M}$ 6-cyano7-nitroquinoxaline-2,3-dione (CNQX), $12.5 \mu \mathrm{M}$ D,L-amino-5-phosphopentanoic acid (APV), and $25 \mu \mathrm{m}$ picrotoxin. For experiments testing the effect of calcium removal in current clamp, $\mathrm{CaCl}_{2}$ was replaced by an equimolar amount of $\mathrm{MgCl}_{2}(2 \mathrm{mM})$, so that the $\mathrm{MgCl}_{2}$ concentration was $3 \mathrm{~mm}$. For experiments testing the removal of external sodium, sodium was completely replaced by equimolar NMDG (151 NMDG, 3.5 $\mathrm{KCl}, 2 \mathrm{~mm} \mathrm{CaCl}_{2}, 1 \mathrm{~mm} \mathrm{MgCl}_{2}, 10 \mathrm{~mm}$ glucose, and $10 \mathrm{~mm}$ HEPES, $\mathrm{pH}$ adjusted to $\mathrm{pH} 7.35$ with NMDG).

In some voltage-clamp experiments (see Figs. 6-10), we used a Csbased internal solution to block potassium currents and allow better isolation of sodium and calcium currents. This internal solution was identical to the standard K-based solution but with equimolar replacement of potassium by cesium. In these experiments, $3 \mathrm{~mm} \mathrm{CsCl}$ was added to the external solutions to block inward-going potassium current and $I_{\mathrm{h}}$ channels.
All experiments were done at $34 \pm 1^{\circ} \mathrm{C}$.

Data analysis. Data analysis was done using pClamp9 and IgorPro version 4.06 (Wavemetrics), using DataAccess (Bruxton) to read pClamp files into Igor. In voltage-clamp experiments, capacitative transients were reduced by the electronic capacitance compensation in the amplifier circuit. For currents recorded using ramp voltage commands, current was plotted as a function of voltage, and voltage-dependent sodium and calcium currents were defined by sensitivity to TTX and Mg replacement for $\mathrm{Ca}$, respectively, after correction of each trace for linear leak current, defined by a linear fit to current in the range from -78 to $-70 \mathrm{mV}$.

Experiments estimating resting potential using reversal of potassium currents in cell-attached patches (see Fig. 4) were based on the method introduced by Verheugen et al. $(1995,1999)$. The pipette solution was the same potassium-methanesulfonate-based solution used for the wholecell experiments. The slice was bathed in an extracellular solution containing $1 \mu \mathrm{M}$ TTX to stop spontaneous firing. Potassium channels in the patch were activated by ramping pipette voltage from +72 to $-108 \mathrm{mV}$ (200 ms ramp). With a typical resting potential near $-55 \mathrm{mV}$, this results in patch membrane potential changing from approximately $-130 \mathrm{mV}$ to $+50 \mathrm{mV}$. The ramp was preceded for $700 \mathrm{~ms}$ by steps to a series of pipette voltages between +25 and $+45 \mathrm{mV}$, followed by a $50 \mathrm{~ms}$ step to $+80 \mathrm{mV}$. These prepulses served to remove inactivation from A-type channels and maximized potassium current during the ramp. Capacitative current was minimized by electronic compensation for pipette capacitance, and residual capacitative current was corrected for during analysis by signal averaging 10-20 steps from +35 to $+80 \mathrm{mV}$ (pipette voltages) to define the capacitative transient, then scaling and subtracting it in a point-bypoint manner during the ramp portion of the record. To accurately determine the voltage at which the voltage-dependent patch current reversed polarity, we averaged 10-20 consecutive sweeps and corrected for the linear seal conductance, determined by extrapolating a fit to the current at pipette voltages between +70 to $+50 \mathrm{mV}$, where there is no voltage-dependent current. This correction was typically $5-10 \mathrm{mV}$ (e.g., Fig. $4 B)$.

In experiments examining the effect of replacing external sodium by NMDG, sodium was completely replaced by NMDG to allow the best quantification of the current carried by sodium. The substitution produced an immediate hyperpolarization of resting potential (in current clamp) or outward shift of holding current (in voltage clamp), occurring as rapidly as the solution change, which was evident by a change in refractive index of the solution in the slice image. After 5-10 min, there was often a subsequent slower change in the opposite direction (depolarization in current clamp or inward shift of holding current in voltage clamp), which was usually poorly reversible. We quantified the effect of NMDG replacement from the initial immediate hyperpolarization or outward shift in current.

Statistics are given as mean $\pm \mathrm{SD}$, and statistical significance tests were done using nonparametric tests (Wilcoxon or Mann-Whitney).

\section{Results}

We recorded firing activity from neurons in the VTA, using transgenic mice in which dopaminergic neurons are identified by expression of enhanced green fluorescent protein (eGFP) driven by the tyrosine hydroxylase promoter (Gong et al., 2003). To isolate intrinsic activity of neurons, we included D-APV, CNQX, and picrotoxin in bath solutions to block synaptic transmission through NMDA, AMPA, and $\mathrm{GABA}_{\mathrm{A}}$ receptors. Dopaminergic VTA neurons identified by eGFP expression fired action potentials spontaneously, usually in a highly regular pacemaker-like fashion (Fig. 1A) as reported previously for dopaminergic VTA neurons in rat (Johnson and North, 1992; Korotkova et al., 2003; Koyama et al., 2005; Margolis et al., 2006, 2008) and mouse (Wolfart et al., 2001; Neuhoff et al., 2002; Ford et al., 2006; Lammel et al., 2008). The average firing rate was $2.1 \pm 1.2 \mathrm{~Hz}(n=90)$. On average, action potentials reached a peak of $+20 \pm 9 \mathrm{mV}$, had a height of $87 \pm 12 \mathrm{mV}$, and an average width at half-amplitude of $1.4 \pm 0.4 \mathrm{~ms}$. The most negative voltage reached during the pace- 
A
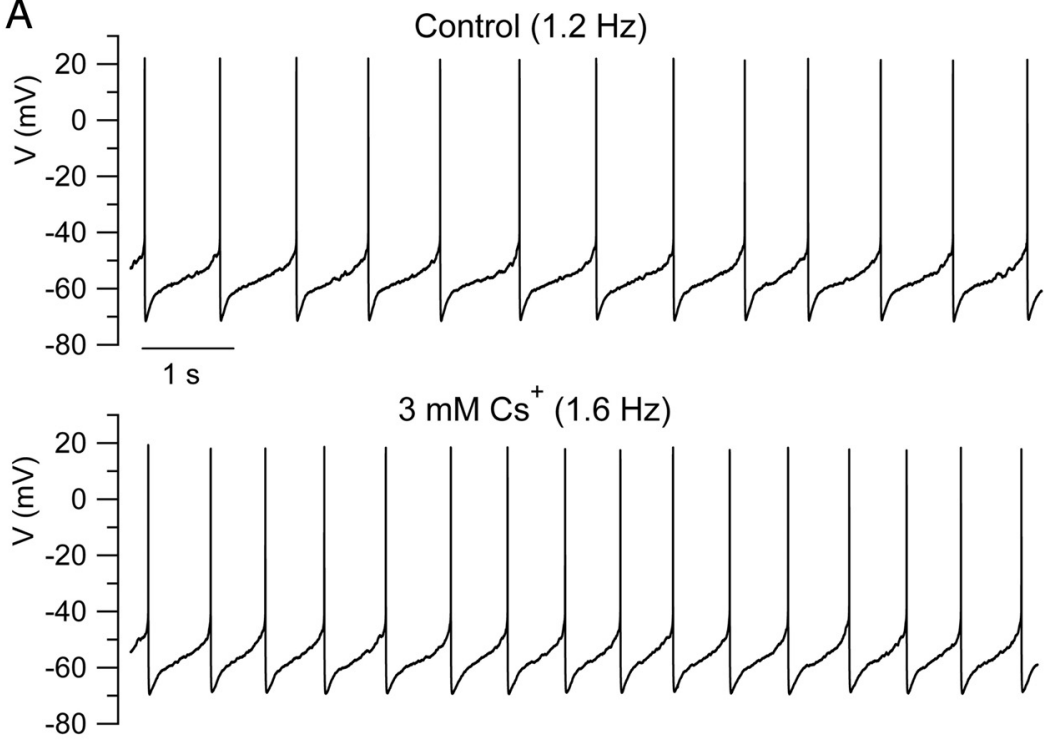

B
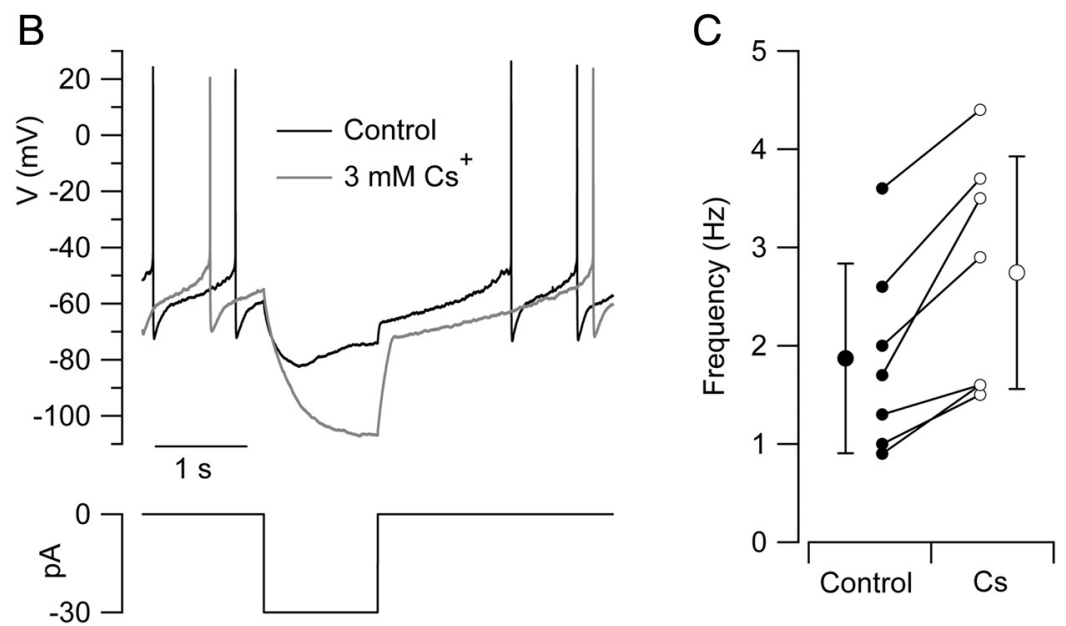

Figure 1. Effect on pacemaking of blocking $I_{\mathrm{h}}$ by external Cs. $\boldsymbol{A}$, Pacemaking in a GFP-positive VTA dopamine neuron before (top) and after (bottom) application of $3 \mathrm{~mm}\left(\mathrm{Ss}\right.$ to block $I_{\mathrm{h}}$. $\boldsymbol{B}$, Responses to hyperpolarizing current injections (same cell as $\boldsymbol{A}$ ), showing the presence of voltage sag in control (black) and inhibition of sag in (s (gray), indicating the effectiveness of $I_{\mathrm{h}}$ block. C, Collected results for the effect of $3 \mathrm{~mm}$ Cs on pacemaking frequency of seven dopaminergic VTA neurons. sponse to a hyperpolarizing current pulse (Fig. $1 B$ ). Such a sag indicative of $I_{\mathrm{h}}$ was seen in all VTA neurons tested (23/23), and application of $3 \mathrm{~mm} \mathrm{CsCl}$ abolished the sag (Fig. $1 B$, gray trace), showing that $\mathrm{Cs}^{+}$blocked $I_{\mathrm{h}}$ even though it did not slow pacemaking. The results with the cell whose records are shown in Figure 1, $A$ and $B$, were typical. On average, the rate of spontaneous firing increased in the presence of $\mathrm{Cs}^{+}$, from an average of $1.9 \pm 1.0$ $\mathrm{Hz}$ in control to $2.7 \pm 1.2 \mathrm{~Hz}$ in $\mathrm{Cs}^{+}(n=$ 7) (Fig. 1C). It seems likely that the increase in firing by $\mathrm{Cs}^{+}$is due to weak block of potassium channels. These results support the previous conclusion that VTA neurons express $I_{\mathrm{h}}$ but that it plays little or no role in normal pacemaking (Neuhoff et al., 2002).

\section{Effect of calcium channel block on pacemaking}

We next focused on the contribution of subthreshold calcium currents to pacemaking. Previous work has shown that blocking calcium current slows or stops pacemaking in dopaminergic SNc neurons (Fujimura and Matsuda, 1989; Grace and Onn, 1989; Harris et al., 1989; Kang and Kitai, 1993a,b; Nedergaard et al., 1993; Mercuri et al., 1994; Chan et al., 2007; Puopolo et al., 2007). To test the importance of calcium current for pacemaking of VTA neurons, we tested the effect of completely replacing external calcium with equimolar magnesium. Replacing calcium with magnesium did not stop spontaneous spiking, but instead speeded it (Fig. $2 A$ ), from an average rate of $1.8 \pm 0.7 \mathrm{~Hz}$ to $6.4 \pm 1.7 \mathrm{~Hz}(n=9)$ (Fig. 2B). Thus, calcium current is clearly not essential for pacemaking in VTA neurons. making cycle (the "trough") was $-67 \pm 6 \mathrm{mV}$, and the average spike threshold (defined as the point at which the $\mathrm{d} V / \mathrm{d} t$ reached $4 \%$ of its maximal value) was $-41 \pm 4 \mathrm{mV}(n=90)$. In most cells, firing was highly regular, with an average coefficient of variation of the interspike interval of $16 \pm 10 \%(n=90)$.

\section{$I_{\mathrm{h}}$ and pacemaking in VTA dopamine neurons}

The hyperpolarization-activated cationic current known as $I_{\mathrm{h}}$ is important for spontaneous electrical activity in cardiac pacemaker cells and some spontaneously active neurons, including a subpopulation of midbrain dopaminergic neurons in the substantia nigra pars compacta (Seutin et al., 2001). Neuhoff et al. (2002) found that dopaminergic VTA neurons express $I_{\mathrm{h}}$, but that blocking it with ZD7288 had no effect on pacemaking. We obtained similar results using external $\mathrm{Cs}^{+}$to block $I_{\mathrm{h}}$. Application of $3 \mathrm{~mm} \mathrm{CsCl}$ did not stop or slow pacemaking (Fig. $1 A$ ). The experiment shown in Figure 1 was typical; $3 \mathrm{~mm} \mathrm{CsCl}$ produced a slight speeding of firing, from 1.2 to $1.6 \mathrm{~Hz}$, and firing remained very regular and pacemaker-like. The neuron in Figure $1 \mathrm{did}$ express $I_{\mathrm{h}}$, as manifested by a "sag" in the voltage change in re-
The speeding of pacemaking when calcium was replaced by magnesium was accompanied by changes in action potential shape (Fig. 2C). Action potentials became broader (measured at half-amplitude, from $1.2 \pm 0.2 \mathrm{~ms}$ in control to $1.7 \pm 0.3 \mathrm{~ms}$ after magnesium replacement, $n=9$ ). In addition, the most negative voltage reached after the spike was less negative after magnesium replacement $(-67 \pm 4 \mathrm{mV}$ in control, $-63 \pm 5 \mathrm{mV}$ after magnesium replacement; $n=9$ ). These changes suggest a decrease in potassium currents driving spike repolarization when magnesium replaces calcium. One possibility is that calcium-activated potassium currents play a significant role in spike repolarization. In addition, replacing calcium with magnesium changes the voltage dependence of A-type $\left(I_{\mathrm{A}}\right)$ potassium current in such a way as to increase steady-state inactivation at typical interspike voltages of -70 to $-55 \mathrm{mV}$ (Koyama and Appel, 2006). A similar shift in the voltage dependence of steady-state $I_{\mathrm{A}}$ inactivation in some types of neurons can be produced from selective inhibition of calcium entry through T-type calcium channels by a mechanism involving KChIP accessory subunits (Anderson et al., 2010). Such a shift in steady-state inactivation would reduce the $I_{\mathrm{A}}$ available to 
help repolarize the spike. As $I_{\mathrm{A}}$ provides a major component of overall potassium current in VTA neurons (Koyama and Appel, 2006a,b; Khaliq and Bean, 2008), spike broadening may reflect in part decreased $I_{\mathrm{A}}$.

Another possible reason for speeding of firing with magnesium replacement for calcium is that magnesium is less effective than calcium in screening negative surface charge (Hille et al., 1975). In principle, this effect could produce a hyperpolarizing shift in sodium channel activation resulting in a more negative spike threshold, which could help speed firing. However, this effect was not significant. Magnesium replacement of calcium resulted in a hyperpolarizing shift of spike threshold by only $-0.3 \pm 2.4 \mathrm{mV}$, from $-42.0 \pm 2.5$ $\mathrm{mV}$ to $-42.3 \pm 3.6 \mathrm{mV}(p=0.81$, Wilcoxon test, $n=9$ ). Thus, this effect does not make a major contribution to the effect of magnesium replacement on firing rate.

If pacemaking were driven by an inward calcium current flowing between spikes, blocking this current would result in a net hyperpolarization during the interspike interval. In fact, however, the average membrane potential during the interspike interval depolarized when calcium was replaced by magnesium, by an average of $2 \pm 3 \mathrm{mV}$, from $-57 \pm 3 \mathrm{mV}$ to $-55 \pm 4 \mathrm{mV}(n=9$; measured in the middle $60 \%$ of the interspike interval).

This does not rule out the possibility that calcium current flows during the interspike interval but suggests that it is outweighed by current through calcium-activated potassium channels, known to be present in dopaminergic VTA neurons (Wolfart et al., 2001; Koyama et al., 2005; Khaliq and Bean, 2008).

The multiple possibilities that can be invoked to help explain the changes in firing rate with magnesium replacement for calcium illustrate the difficulty in interpreting such current-clamp results and help motivate voltage-clamp experiments, in which changes of different components of current should be easier to distinguish. However, whatever the cause of the faster firing in magnesium, the continuation of pacemaking with no external calcium makes it seem highly unlikely that calcium entry through voltage-dependent calcium channels is the major mechanism for pacemaking.

\section{Background sodium leak current}

The resting potential of neurons varies widely among different types of neurons. A particularly simple mechanism of pacemaking would result if the resting potential of a neuron were positive to the spike threshold. Obviously, a spontaneously active neuron does not have a true resting potential, but an approximate measurement can be made if spontaneous firing is silenced by application of TTX to block the voltage-dependent sodium channels underlying spiking. When this is done, many pacemaking neurons, including pedunculopontine neurons (Takakusaki and Kitai, 1997), suprachiasmatic nucleus neurons (Pennartz et al., 1997; Jackson et al., 2004), subthalamic nucleus neurons (Bevan
Control

$0 \mathrm{Ca}, 3 \mathrm{mM} \mathrm{Mg}$

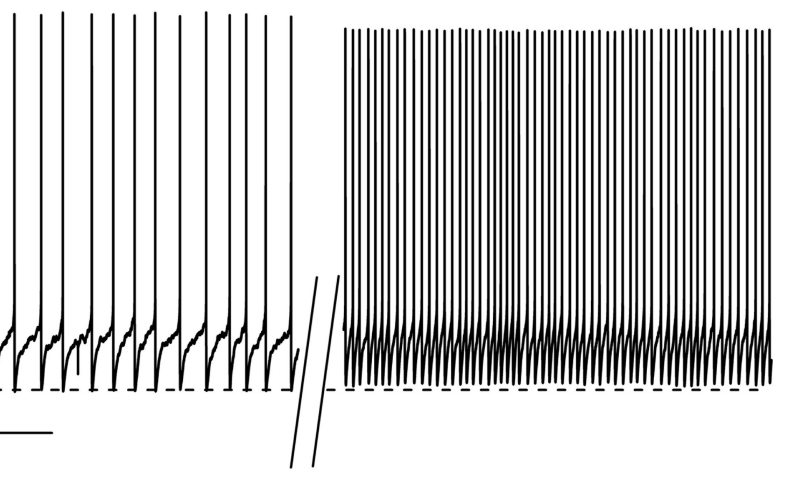

$4 \mathrm{~s}$

C

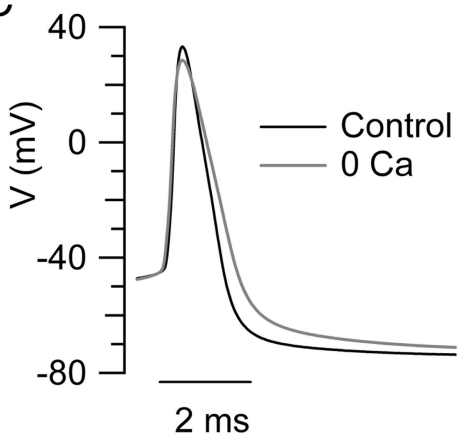

Figure 2. Pacemaking is not inhibited by complete removal of calcium from extracellular solution. $\boldsymbol{A}$, Spontaneous firing before and after replacement of extracellular Ca (2 mm) by an equimolar amount of $\mathrm{Mg}$. Dashed line is drawn at $-74 \mathrm{mV}$, the most negative voltage reached during control firing; the most negative voltage during firing in the Ca-free solution is $\sim 2 \mathrm{mV}$ depolarized. $\boldsymbol{B}$, Collected results for the effect of calcium replacement by $\mathrm{Mg}$ on pacemaker frequency in nine neurons. $\boldsymbol{C}$, Action potential waveforms before (black) and after (gray) replacement of Ca by $\mathrm{Mg}$ (same cell as in $\boldsymbol{A}$ ).

and Wilson, 1999; Atherton et al., 2008), and tuberomammillary nucleus neurons (Taddese and Bean, 2002), have resting potentials in the range of -55 to $-50 \mathrm{mV}$. This is negative to the typical spike threshold near $-45 \mathrm{mV}$, but considerably more depolarized than the typical resting potentials of nonpacemaking neurons such as hippocampal pyramidal neurons [-68 $\mathrm{mV}$ (Kaczorowski et al., 2007); - $84 \mathrm{mV}$ (Fricker et al., 1999)], cortical pyramidal neurons [ $-76 \mathrm{mV}$ (Breton and Stuart, 2009)], or cerebellar granule neurons [ $-80 \mathrm{mV}$ (Brickley et al., 2007)].

To measure the resting membrane potential in VTA neurons, we silenced spiking by adding TTX to the bath solution (Fig. $3 A$ ). In dopaminergic neurons in the substantia nigra pars compacta, the membrane potential often continues to oscillate in the presence of TTX; these oscillations are calcium dependent and are sometimes large enough to constitute rhythmic calciummediated spikes reaching near $0 \mathrm{mV}$ (Kang and Kitai, 1993a,b; Nedergaard et al., 1993, Wilson and Callaway, 2000; Puopolo and Bean, 2007; Chan et al., 2007). However, in agreement with Chan et al. (2007), we almost never saw such oscillations in VTA neurons. In 11 of 12 neurons tested, application of TTX resulted in a stable resting potential, with an average value of $-56 \pm 5 \mathrm{mV}$ $(n=11)$. Only one neuron showed oscillations of membrane potential in TTX, with the membrane potential oscillating with an amplitude of $\pm 4 \mathrm{mV}$ around a mean of $-37 \mathrm{mV}$. The lack of calcium-dependent oscillations in most VTA neurons is consistent with the idea that subthreshold voltage-dependent calcium currents are smaller and less important for pacemaking in VTA neurons than in SNc neurons. 
A

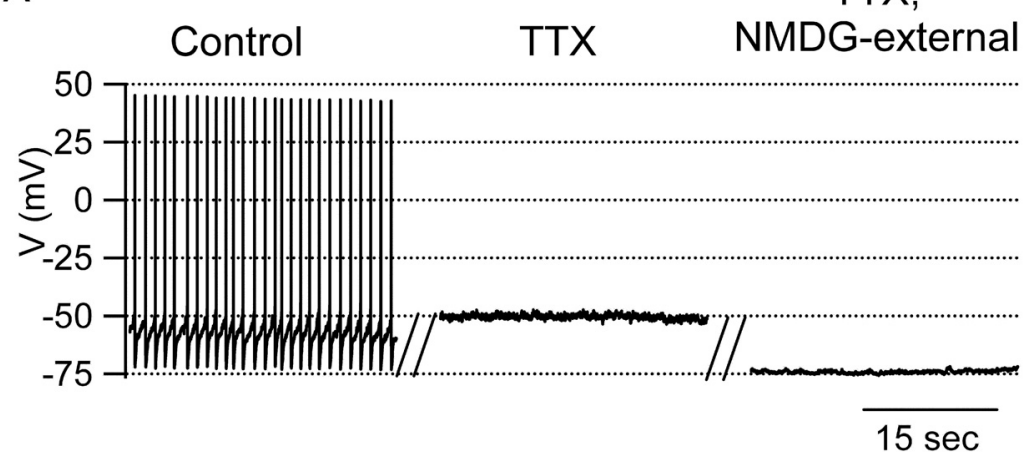

B

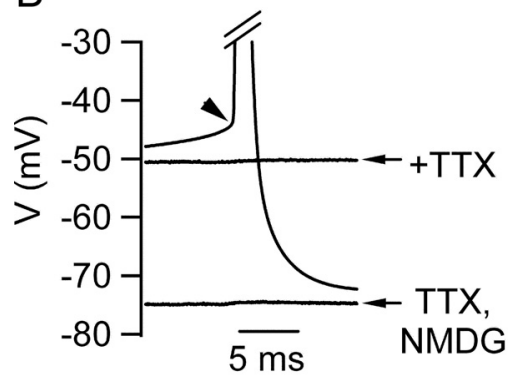

C

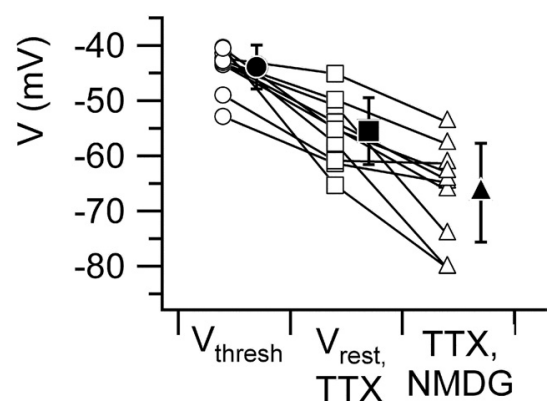

Figure 3. Na dependence of resting membrane potential of VTA neurons. A, Application of $1 \mu \mathrm{M} T \mathrm{TX}$ to a dopaminergic VTA neuron resulted in a stable resting potential of $-51 \mathrm{mV}$. Replacement of external Na by equimolar NMDG then resulted in hyperpolarization to $-74 \mathrm{mV} . \boldsymbol{B}$, Comparison of resting potential ( $-51 \mathrm{mV}$ ) to spike threshold ( $-44 \mathrm{mV}$, arrow) for cell shown in $A$. Action potential shown in $B$ is an average of 34 spike waveforms. $\boldsymbol{C}$, Collected results for the same experiment repeated in 10 dopaminergic VTA neurons.

the seal between the tip of the recording pipette and the cell membrane. Such leak would result in a shunting of the resting potential and an underestimate in its measurement. Measurement of changes in membrane potential like those produced by NMDG substitution for sodium might also be subject to this error, because the resistance of the seal might be affected by the ionic composition of the solutions. For example, if the resistance of the pipette-cell seal were increased by NMDG replacement for sodium, this could produce an apparent hyperpolarization even without a true change in resting potential.

To take account of this possibility, we used a technique for making noninvasive measurements of membrane potential that takes advantage of the high density of voltage-dependent potassium channels often present in excitable cells to measure membrane potential based on the reversal of current through potassium channels in a cell-attached patch (Verheugen et al., 1995, 1999). Figure 4 illustrates the use of this technique in a VTA dopaminergic neuron. We made cell-attached patch recordings using a pipette solution containing $140 \mathrm{~mm}$ potassium, similar to the expected concentration of potassium within the cytoplasm. Recordings were

Figure $3 B$ compares the resting potential (in the presence of TTX) with the spike threshold. We used a definition of spike threshold as the voltage at which rate of depolarization $(\mathrm{d} V / \mathrm{d} t)$ reached $4 \%$ of the maximum $\mathrm{d} V / \mathrm{d} t$ during the action potential upstroke. Although this definition is somewhat arbitrary, it corresponded well to the point on the voltage trace at which the depolarization appeared by eye to become abrupt (Fig. $3 B$, arrow). The result for the cell in Figure 3, $A$ and $B$, was typical; the resting potential $(-51 \mathrm{mV})$ was $\sim 7 \mathrm{mV}$ negative to the spike threshold $(-44 \mathrm{mV})$. On average, the resting potential was $12 \pm$ $5 \mathrm{mV}$ negative to the spike threshold, which in this group of neurons averaged $-44 \pm 4 \mathrm{mV}$ (Fig. $3 C)(n=10)$.

The resting membrane potential in the presence of TTX is very depolarized compared to the equilibrium potential for potassium ions (approximately $-95 \mathrm{mV}$ ), suggesting that there might be a resting sodium conductance not sensitive to TTX. We tested this possibility by replacing the sodium in the external bath solution with an equimolar concentration of the large cation $N$-methyl-Dglucamine (NMDG), which is impermeant in most sodiumselective channels. In the experiment shown in Figure 3, $A$ and $B$, the membrane potential hyperpolarized from $-51 \mathrm{mV}$ to -74 $\mathrm{mV}$ when sodium was replaced by NMDG. Such an effect was seen consistently; on average, NMDG replacement caused a hyperpolarization of $-11 \pm 8 \mathrm{mV}$, from $-56 \pm 5$ to $-68 \pm 8 \mathrm{mV}$ (Fig. 3C) $(n=10)$. These results suggest that a background sodium leak conductance contributes significantly to a depolarized resting membrane potential in VTA neurons.

\section{Noninvasive measurements of membrane potential from cell-attached recordings}

A general difficulty in interpreting measurements of membrane potential is that they might be affected by leak of current around made from cells bathed in an extracellular solution containing 1 $\mu \mathrm{M}$ TTX to stop spontaneous firing. The pipette voltage was ramped from +72 to $-108 \mathrm{mV}$. The lower trace in Figure $4 \mathrm{~A}$ shows the current evoked by this protocol, signal averaged from 17 consecutive traces to reduce noise. Current flowing out of the pipette is plotted as negative, corresponding to positive ions flowing inward into the cell across the patch membrane. At pipette voltages from +72 to $+40 \mathrm{mV}$, the ramp-evoked current was very small. At these pipette voltages, the patch membrane is hyperpolarized relative to the resting potential, so voltagedependent potassium channels in the patch are closed and the current likely represents mainly the seal resistance. In the cell of Figure 4, a linear fit to the current as a function of voltage in this voltage range corresponded to a seal resistance of $32 \mathrm{G} \Omega$ (Fig. $4 B$, gray trace). As pipette voltage was made more negative, corresponding to depolarization of the patch, the current suddenly became inward and increased to a peak ranging from 20 to $60 \mathrm{pA}$. This sudden increase in inward current likely reflects opening of A-type potassium channels, as they represent the dominant outward current in whole-cell recordings of VTA neurons (Koyama and Appel, 2006a,b; Khaliq and Bean, 2008). Following the peak, the inward current decreased and eventually reversed polarity to become outward. The voltage across the patch membrane at which current reverses polarity should correspond to the reversal potential for potassium ions, which would be near $0 \mathrm{mV}$ for a pipette solution with nearly the same potassium concentration as the cytoplasmic solution. Thus, the reversal of the voltageactivated potassium current should occur when the pipette voltage is equal to the intracellular voltage. To most accurately determine the voltage at which current through voltagedependent channels reversed polarity, we averaged multiple sweeps. Figure $4 B$ shows the ramp-evoked current plotted as a 
function of pipette voltage (black trace) averaged from 17 sweeps. In addition, we corrected for the expected "leak" current through the seal resistance (gray line), which was determined from the fit to the current at pipette voltages from +70 to $+50 \mathrm{mV}$ and extrapolated. The reversal potential of the voltage-dependent current after correcting for the linear leak current was $-51 \mathrm{mV}$. In collected results, the resting potential in the presence of TTX measured in this way averaged $-57 \pm 8 \mathrm{mV}(n=9)$. This is essentially identical to the values of resting potential in TTX measured with whole-cell recording in a separate population of cells $(-56 \pm 5 \mathrm{mV}, n=11)$.

Next, we used this technique to test for changes in resting potential when replacing external sodium by NMDG. Figure $4 C$ shows an example, plotting the inferred membrane potential as the extracellular solution was changed to one of the same ionic composition but with NMDG replacing sodium. The inferred resting potential in this neuron hyperpolarized from -51 to $-65 \mathrm{mV}$ with NMDG replacement for sodium. In collected results (Fig. $4 D$ ), we found that cells hyperpolarized by an average of $-13 \pm 7 \mathrm{mV}$ in response to sodium replacement with NMDG, from an average of $-57 \pm 8 \mathrm{mV}$ to $-70 \pm$ $9 \mathrm{mV}(p<0.01$, Wilcoxon test). This is very similar to the hyperpolarization of $-11 \pm 8 \mathrm{mV}$ seen in the whole-cell recording experiments.

This technique gives a measurement of membrane potential that should be unaffected by the imperfect seal between the pipette and the membrane, because the current from leak around the pipette has an ohmic current-voltage relationship that can be defined at negative patch voltages and then be extrapolated and subtracted before measuring the reversal of the voltage-dependent potassium current. In addition, the technique gives a direct measurement of the seal resistance, so we were able to determine whether this was affected by replacing sodium with NMDG. We found that there was very little effect. On average, the seal resistance was $13 \pm 7 \mathrm{G} \Omega$ in control and $12 \pm 6 \mathrm{G} \Omega$ after NMDG replacement ( $p=0.73, n=$ 9 , Wilcoxon test).

These results show that resting potentials measured noninvasively are similar to those measured with whole-cell recording using the standard potassium methanesulfonate-based internal solution, suggesting that dialysis with this solution preserves the essential conductances controlling resting potential. In addition, the hyperpolarization produced by NMDG replacement for sodium was nearly identical with the two methods of recording, showing that it does not simply reflect a change in seal resistance.

\section{Steady-state subthreshold sodium and calcium currents}

These measurements show that with voltage-dependent sodium channels blocked by TTX, dopaminergic VTA neurons rest near -60 to $-55 \mathrm{mV}, 10-15 \mathrm{mV}$ hyperpolarized to the spike thresh- old near $-45 \mathrm{mV}$. What currents are responsible for the spontaneous depolarization from $-60 \mathrm{mV}$ to threshold during pacemaking? One obvious candidate is steady-state TTXsensitive "persistent" sodium current, which is often present in this voltage range in central neurons. We characterized the voltage dependence and magnitude of steady-state TTX-sensitive sodium current using slow $(10 \mathrm{mV} / \mathrm{s})$ voltage ramps. Figure $5 \mathrm{~A}$ shows the currents elicited by a $10 \mathrm{mV} / \mathrm{s}$ ramp from -78 to -38 $\mathrm{mV}$ using internal and external solutions with physiological ionic composition. The ramp-evoked current was linear in the range from -78 to approximately $-65 \mathrm{mV}$, with a slope corresponding to an input resistance of $0.95 \mathrm{G} \Omega$. Positive to $-65 \mathrm{mV}$, there was a component of inward current that reached a peak near -40 $\mathrm{mV}$. Application of $300 \mathrm{~nm}$ TTX blocked the inward component of ramp-evoked current, suggesting that this component represents steady-state or persistent Na current. Figure $5 B$ shows the isolated TTX-sensitive current. The average magnitude at -40 $\mathrm{mV}$ was $-56 \pm 27 \mathrm{pA}(n=22)$. When converted to a conductance to take account of the variable driving force, the voltage dependence of the steady-state sodium conductance could be fit well by a Boltzmann equation (Fig. $5 C$ ). In collected results, the maximal steady-state conductance was $0.59 \pm 0.28 \mathrm{nS}$, with an average midpoint of $-50 \pm 2 \mathrm{mV}$ and a slope factor of $-3.7 \pm 0.6$ 

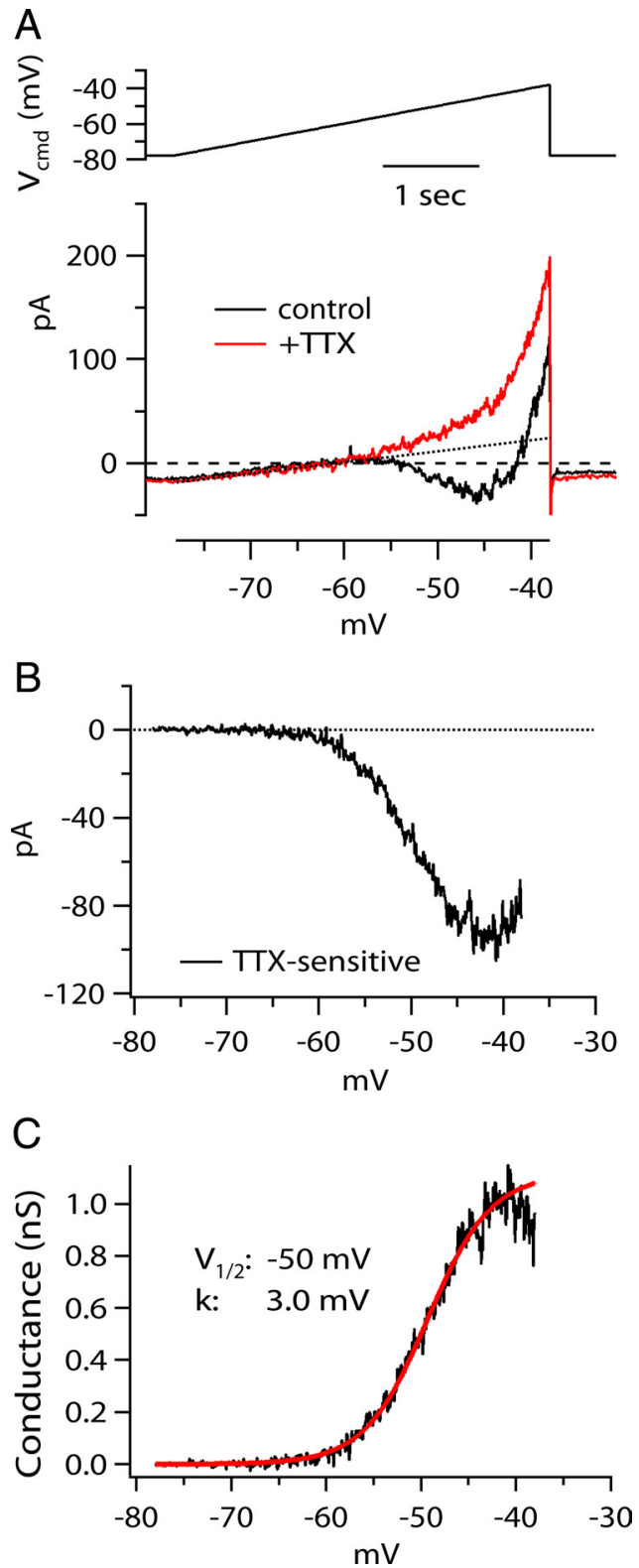

Figure 5. Current evoked in voltage clamp by slow a ramp $(10 \mathrm{mV} / \mathrm{s})$ from -78 to $-38 \mathrm{mV}$ under physiological ionic conditions. $\boldsymbol{A}$, Raw currents before (black) and after (red) application of $1 \mu \mathrm{m}$ TTX. Each trace was signal averaged from two sweeps and smoothed. Dotted line, Linear fit to control current between -78 and $-70 \mathrm{mV}$, extrapolated. Line corresponds to input resistance of $0.95 \mathrm{G} \Omega$. Currents recorded using internal $\mathrm{K}$ methanesulfonate-based solution and external Tyrode's solution. $\boldsymbol{B}$, TTX-sensitive current obtained by subtracting the traces in $\boldsymbol{A}$ plotted as a function of voltage. $C$, Voltage dependence of steady-state sodium conductance, obtained by converting TTX-sensitive sodium current in $\boldsymbol{B}$ to a conductance (using a reversal potential of $+51 \mathrm{mV})$. The solid line is plotted according to $G=G_{\max } /[1-\exp (-(V-$ $\left.\left.V_{\mathrm{h}}\right) / k\right)$, where $G_{\max }$ is the maximal conductance $(1.1 \mathrm{nS}), V$ is the voltage, $V_{\mathrm{h}}$ is the midpoint $(-50 \mathrm{mV})$, and $k$ is the slope factor $(3.0 \mathrm{mV})$.

$\mathrm{mV}(n=22)$. The dependence of the steady-state TTX-sensitive sodium conductance on voltage is steep ( $e$-fold increase for 3.7 $\mathrm{mV}$ ), equally steep as the voltage dependence typical of transient sodium current as a function of voltage [e.g., $e$-fold for $3.9 \mathrm{mV}$ in the squid giant axon (Hodgkin and Huxley, 1952)].

In recordings like that in Figure 5 with slow ramps to define steady-state current with physiological ionic conditions, subthreshold voltage-dependent calcium current would be manifested as a component of subthreshold voltage-activated inward
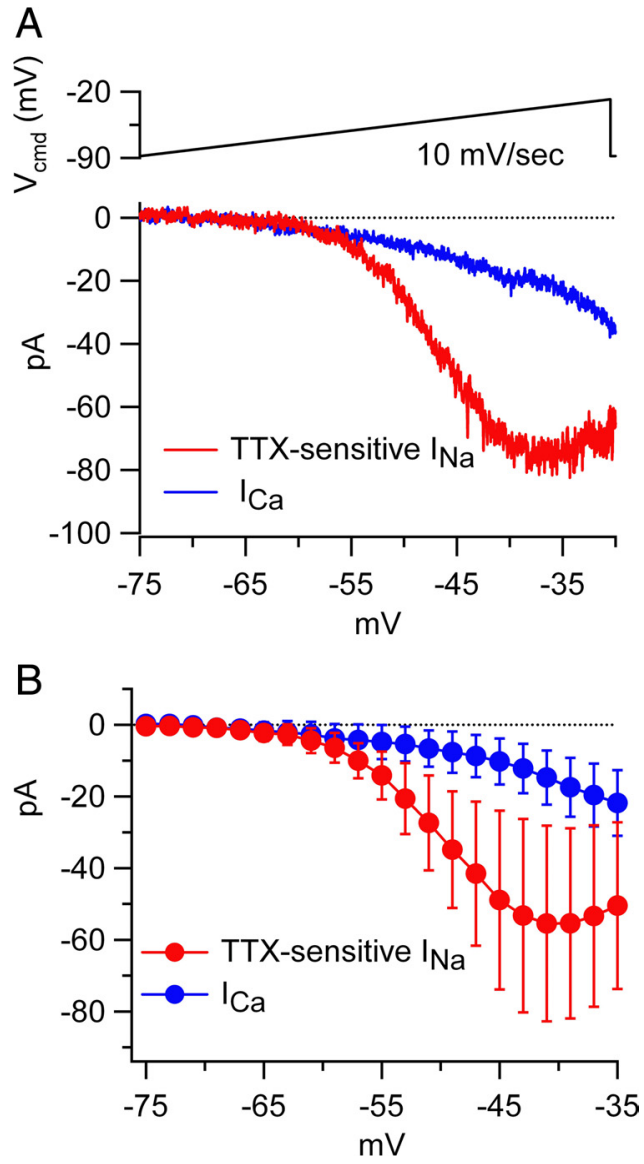

Figure 6. Comparison of subthreshold sodium and calcium currents. A, Ramp current sensitive to TTX (red) and current in the presence of TTX sensitive to calcium substitution by equimolar magnesium (blue), recorded from same cell. Currents recorded using internal Cs methanesulfonate-based solution. Traces were corrected for leak, as shown in Figure 5, signal averaged, and smoothed. $\boldsymbol{B}$, Collected results for ramp-evoked currents in a population of neurons. Data points indicate mean $\pm S D$ for ramp current averaged across multiple cells (TTX-sensitive $I_{\mathrm{Na}^{\prime}} n=21 ; I_{\mathrm{Ca}^{\prime}} n=14$ ).

current remaining in TTX. In most cells, no such current was evident (e.g., Fig. 5A, red trace), and in the few cells in which it was present, it was at most a few picoamperes. To investigate the possibility that subthreshold calcium current is actually substantial but masked by overlapping outward potassium current, we did experiments using an internal Cs-based solution to inhibit potassium currents (Fig. 6). With Cs-based solutions, TTXsensitive subthreshold currents were essentially identical to those recorded with potassium-based internal solutions. However, there was also a component of inward current remaining in the presence of TTX. This current was abolished by substitution of magnesium for calcium, consistent with being calcium current. Subthreshold calcium current began to activate detectably near $-60 \mathrm{mV}$ and increased continuously up to $-18 \mathrm{mV}$. Rampevoked calcium current was always smaller than the TTXsensitive sodium current in the same cell. Figure $6 B$ compares the average current through voltage-dependent calcium channels with the TTX-sensitive sodium current, measured using the same internal Cs-based solution. The calcium current was much smaller than TTX-sensitive sodium current $(-0.8 \pm 1.6 \mathrm{pA}$ vs $-4.4 \pm 3.5 \mathrm{pA}$ at $-61 \mathrm{mV},-10 \pm 6 \mathrm{pA}$ vs $-49 \pm 25 \mathrm{pA}$ at -45 $\mathrm{mV} ; n=14$ for Mg-sensitive current and $n=21$ for TTXsensitive current). 

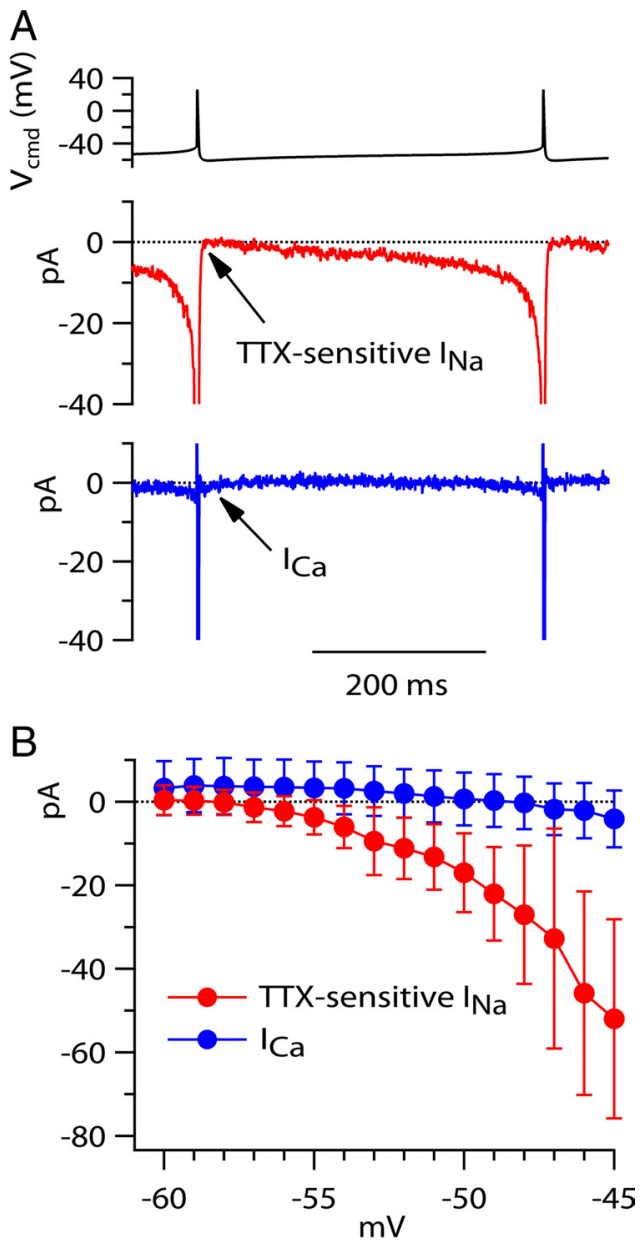

Figure 7. TTX-sensitive sodium current and calcium current (obtained by magnesium substitution for calcium) evoked by action potential waveforms. A, Current blocked by $1 \mu \mathrm{m}$ TTX (red) evoked by pacemaking cycle waveform (top) and current sensitive to substitution of $\mathrm{Mg}$ for Ca (blue). Currents recorded using internal Cs methanesulfonate-based solution. B, Averaged results for TTX-sensitive and calcium current during the interspike interval, plotted as a function of voltage (TTX-sensitive $I_{\mathrm{Na} \prime} n=21 ; I_{\mathrm{Ca}^{\prime}} n=13$ ).

These results show that there is voltage-dependent calcium current present at subthreshold voltages, but it is much smaller than TTX-sensitive sodium current. In addition, net inward calcium current is not detectable in most cells when using physiological solutions, most likely because it is outweighed by overlapping potassium currents. These observations in voltage clamp are consistent with the current-clamp results showing that pacemaking is not disrupted by removal of all external calcium.

\section{Sodium and calcium currents during the interspike interval}

To directly measure the contributions of various currents to the spontaneous depolarization underlying pacemaking, we used the action potential clamp technique (Llinás et al., 1982), in which the voltage waveform recorded during pacemaking is used as the command waveform in voltage-clamp mode and individual ionic currents flowing throughout the pacemaking cycle are isolated by ionic substitution or pharmacological block. Figure 7 shows results from experiments in which the action potential clamp technique was used to quantify sodium current and calcium current flowing in the interspike interval. For the command voltage, we used action potentials recorded from a VTA neuron chosen to have typical parameters of frequency, spike width, trough potential, and interspike voltage trajectory. The voltage trajectory dur- ing a pacemaking cycle was signal averaged by aligning individual spikes at their peaks and signal averaging the voltage trajectories before and after the spike. Currents in response to this voltage trajectory were recorded with a cesium-based intracellular solution to eliminate calcium-activated potassium current (as well as other potassium currents).

Figure $7 A$ shows the voltage-dependent sodium current and calcium current flowing during the pacemaking cycle. Voltagedependent sodium current was determined by subtracting currents before and after application of $1 \mu \mathrm{M}$ TTX. As expected, TTX-sensitive sodium current was maximal during the rising phase of the action potential, reaching $\sim 1 \mathrm{nA}$. Detectable sodium current also flowed at subthreshold voltages during the interspike interval (Fig. 7A, middle). Sodium current was zero immediately after the action potential, but increased in magnitude during the interspike interval to be approximately $-3 \mathrm{pA}$ at $-55 \mathrm{mV}$ and $-57 \mathrm{pA}$ at $-45 \mathrm{mV}$.

The time course of calcium current during the pacemaking cycle was determined by replacing calcium by magnesium in the presence of TTX (with a background of intracellular cesium to inhibit calcium-activated potassium currents). Calcium current was largest during the falling phase of the action potential, reaching a peak of $\sim 200 \mathrm{pA}$ in the cell shown in Figure $7 A$. In contrast to sodium current, calcium current was near zero during most of the interspike interval, from after the action potential until shortly before spike threshold (Fig. 7A, bottom).

Figure $7 B$ shows collected results comparing calcium current with TTX-sensitive sodium current during the interspike interval. TTX-sensitive sodium current was much larger than calcium current. At $-55 \mathrm{mV}$, TTX-sensitive current was $-4 \pm 4 \mathrm{pA}$ compared to a calcium current of $3 \pm 6 \mathrm{pA}$; at $-50 \mathrm{mV}$, TTX-sensitive current was $-17 \pm 9 \mathrm{pA}$ compared to a calcium current of $1 \pm 6 \mathrm{pA}$; and at $-45 \mathrm{mV}$, which was near the average spike threshold, TTX-sensitive current was $-52 \pm 24 \mathrm{pA}$ compared to a calcium current of $-4 \pm 7 \mathrm{pA}(n=21$ for TTX-sensitive current and $n=$ 13 for calcium current). Thus, TTX-sensitive voltage-dependent sodium current is much larger than calcium current over the entire interspike interval.

\section{Background sodium leak current measured during action potential waveform recordings}

The hyperpolarization of resting potential when NMDG replaces sodium in the presence of TTX suggests a significant background sodium "leak" conductance. We quantified the background sodium leak current during the pacemaking cycle by using NMDG substitution for sodium in the presence of TTX. In the experiment shown in Figure 8, we compared the TTX-sensitive current during pacemaking to the current sensitive to sodium replacement with NMDG, recorded from the same neuron in the presence of TTX. In contrast to the TTX-sensitive current, which increased during the interspike interval, the NMDG-sensitive background current was large throughout the entire interspike interval, at $\sim 8 \mathrm{pA}$, but changed little in amplitude throughout the interspike interval. The amplitude of the NMDG-sensitive current was larger than the TTX-sodium current for most of the interspike interval, until shortly before spike threshold. In collected results from a population of neurons in which both measurements were made, at $-60 \mathrm{mV}$, near the trough potential, the average NMDG-sensitive current was $-21 \pm 13 \mathrm{pA}$, while the TTX-sensitive current was minimal, at $-1 \pm 4 \mathrm{pA}$ on average $(n=12)$. The NMDG-sensitive current remained larger than the TTX-sensitive current up to a voltage of $-50 \pm 3 \mathrm{mV}$ on average. Above $-50 \mathrm{mV}$, the amplitude of TTX-sensitive current in- 

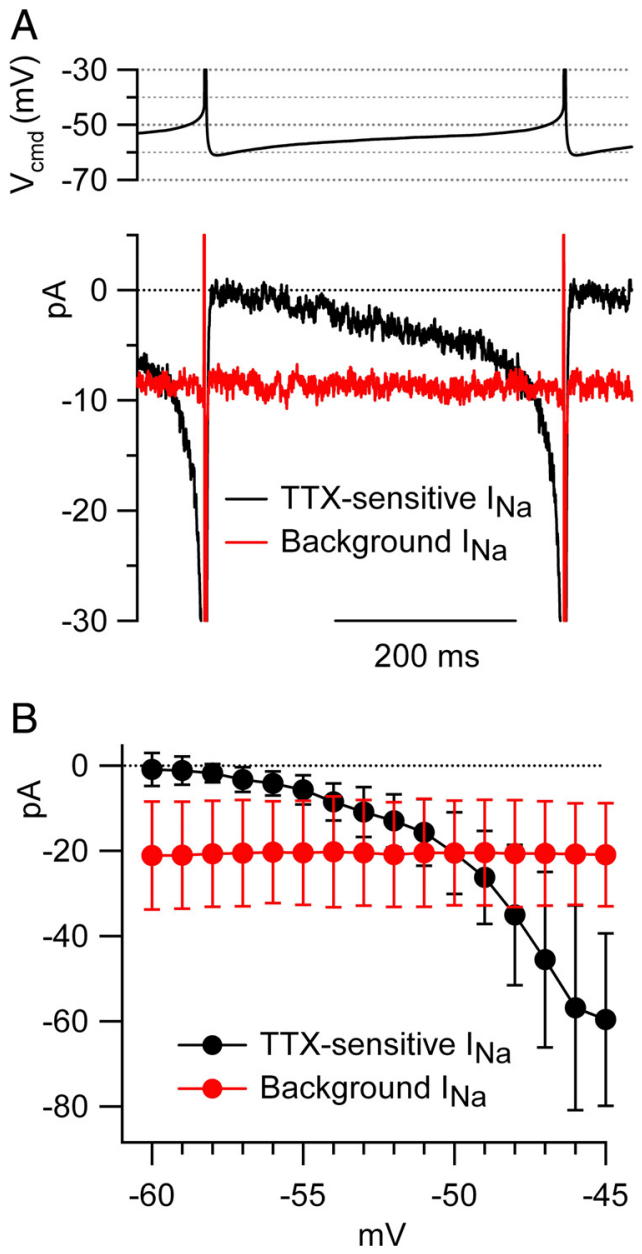

Figure 8. Comparison of background sodium leak current and TTX-sensitive current at subthreshold voltages during pacemaking. $A$, Current evoked by pacemaking cycle waveform sensitive to TTX (black) and background current sensitive to replacement of external Na with NMDG in the presence of TTX (red) recorded in same cell. $\boldsymbol{B}$, Averaged results of paired current recordings for TTX-sensitive current and background sodium current during the interspike interval, plotted as a function of voltage $(n=12)$.

creased rapidly, surpassing the NMDG-sensitive current. Therefore, these experiments show that the background sodium leak current is the dominant inward current at subthreshold voltages, and is likely to play a critical role in pacemaking in VTA dopamine neurons.

\section{Voltage dependence of background sodium leak current}

It was striking that the background sodium leak current defined by NMDG replacement for sodium showed little dependence on voltage when elicited by the pacemaking waveform. To examine the voltage dependence of this current over a wider voltage range, we used voltage ramps from -88 to $-28 \mathrm{mV}$. Figure $9 A$ shows an example comparing the TTX-sensitive current over this voltage range to the background sodium leak current, determined by sodium replacement with NMDG, recorded from the same neuron in the presence of TTX. The background sodium current showed only mild voltage dependence over the voltage range from -88 to $-28 \mathrm{mV}$. In collected results (Fig. $9 B$ ), it decreased from $-26 \pm 20 \mathrm{pA}$ at $-88 \mathrm{mV}(n=9)$ to a minimum of $-17 \pm$ $11 \mathrm{pA}$ at $-50 \mathrm{mV}$, and then increased somewhat at potentials depolarized to $-50 \mathrm{mV}$, to $-26 \pm 13 \mathrm{pA}$ at $-30 \mathrm{mV}$.

The shape of the current-voltage relationship of background sodium current (as defined by replacement of sodium by



B

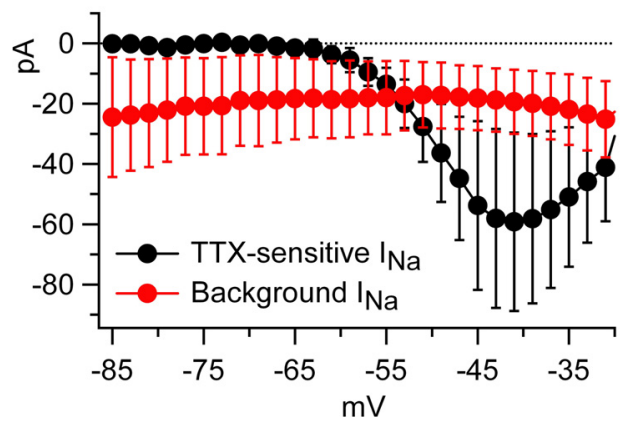

Figure 9. Voltage dependence of background sodium leak current and TTX-sensitive current. $\boldsymbol{A}$, TTX-sensitive (black) and background leak current sensitive to replacement of external Na with NMDG in the presence of TTX (red) evoked by $10 \mathrm{mV} / \mathrm{s}$ ramps from -88 to $-28 \mathrm{mV}$. $\boldsymbol{B}$, Averaged results of paired current recordings for TTX-sensitive current and background current evoked by ramps $(n=9)$.

NMDG) is suggestive of multiple components. One component appears to decrease by $\sim 25 \%$ from $-85 \mathrm{mV}$ to $-50 \mathrm{mV}$, which would be consistent with a change in driving force on sodium ions flowing through a non-voltage-dependent conductance. A second component of current appears to increase in a voltagedependent manner depolarized to $-50 \mathrm{mV}$. The origin of this component is unclear. It could reflect a differential effect of NMDG compared to sodium on affecting the size of a voltagedependent potassium conductance. Although the experiment was done with intracellular cesium replacing potassium, some potassium channels are weakly permeable to cesium and might be depressed by external sodium. In this case the apparent increase in sodium background current depolarized to $-50 \mathrm{mV}$ would be an artifact of imperfect subtraction between the NMDG- and sodium-based solutions. However, it is the current negative to $-50 \mathrm{mV}$ that is most relevant for pacemaking, and this current seems consistent with a non-voltage-dependent conductance that passes sodium ions.

For both background sodium current and TTX-sensitive sodium current, the size of the current at various voltages was very similar when determined by slow voltage ramps (Fig. 9) as when determined by pacemaking waveforms (Fig. 8), suggesting that the currents during the pacemaking cycle are nearly at steady state.

\section{Background sodium current in $\mathrm{SNc}$ neurons}

These results show that background sodium leak current is the dominant current driving pacemaking in VTA neurons (at least up to 
$-50 \mathrm{mV})$. Such a current sensitive to NMDG replacement for sodium has not been described in SNc neurons, but typical resting potentials of SNc neurons (measured when voltage oscillations in TTX are silenced by blocking calcium current) are between $-65 \mathrm{mV}$ and $-43 \mathrm{mV}$ (Nedergaard et al., 1993; Chan et al., 2007; Puopolo et al., 2007; Guzman et al., 2009), raising the possibility of a significant resting sodium conductance. A recent computer model of pacemaking in SNc neurons proposed a role for a background cation conductance that becomes especially important when L-type calcium current is blocked (Guzman et al., 2009). We therefore examined whether a background sodium current is present in SNc as well as VTA neurons. We found that such a current is present in some but not all SNc neurons and when present is generally much smaller than in VTA neurons. Figure $10 \mathrm{~A}$ shows an example of an SNc neuron in which replacing sodium by NMDG (in the presence of TTX) resulted in a reduction of inward current over voltages from -85 to $-30 \mathrm{mV}$, consistent with a background sodium leak current not sensitive to TTX. Figure $10 \mathrm{~B}$ shows records from another SNc neuron in which no such current was evident. In collected results (Fig. 10C), there was clear background sodium current $(>5 \mathrm{pA}$, measured at -85 $\mathrm{mV}$ ) with this ionic substitution in only 9 of 21 SNc neurons, while such a current was present in 27 of 29 VTA neurons tested. Also, when present in SNc neurons, the current density was generally small compared to VTA neurons (Fig. 10C). On average, the current in $\mathrm{SNc}$ neurons that did have measurable current was $-0.42 \pm 0.45 \mathrm{pA} / \mathrm{pF}$ $(n=9)$ at $-85 \mathrm{mV}$, compared to $-1.45 \pm 2.37 \mathrm{pA} / \mathrm{pF}(n=27)$ in VTA neurons ( $p=0.016$, Mann-Whitney). Including cells with no current, the average current in SNc neurons was $-0.19 \pm 0.35$ $\mathrm{pA} / \mathrm{pF}(n=21)$ compared to $-1.35 \pm 2.31 \mathrm{pA} / \mathrm{pF}(n=29)$ in VTA neurons ( $p=0.0001$, Mann-Whitney).

\section{Discussion}

Our results show that pacemaking in VTA dopamine neurons depends primarily on two sodium-permeable conductances: a voltage-independent background sodium leak current and a TTX-sensitive, voltage-dependent sodium current. The background sodium leak current is the largest depolarizing current for most of the interspike interval, between approximately $-65 \mathrm{mV}$ and approximately $-55 \mathrm{mV}$. When the voltage reaches approximately $-60 \mathrm{mV}$, TTX-sensitive sodium current begins to be activated, and it becomes the dominant inward current from approximately $-55 \mathrm{mV}$ to the spike threshold near $-45 \mathrm{mV}$.

\section{Comparison with $\mathrm{SNc}$ neurons}

Although there is some voltage-dependent calcium current that flows at subthreshold voltages in VTA neurons, it is always much smaller than TTX-sensitive sodium current at the same voltages. The small size of the subthreshold calcium current relative to

C
$\mathrm{B}$
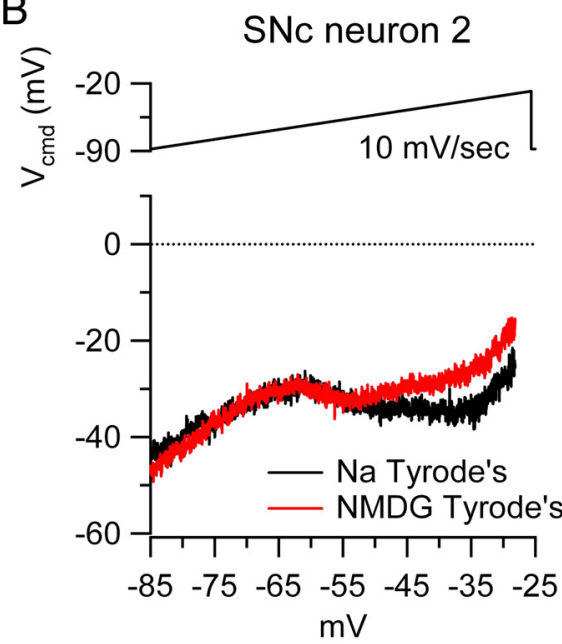

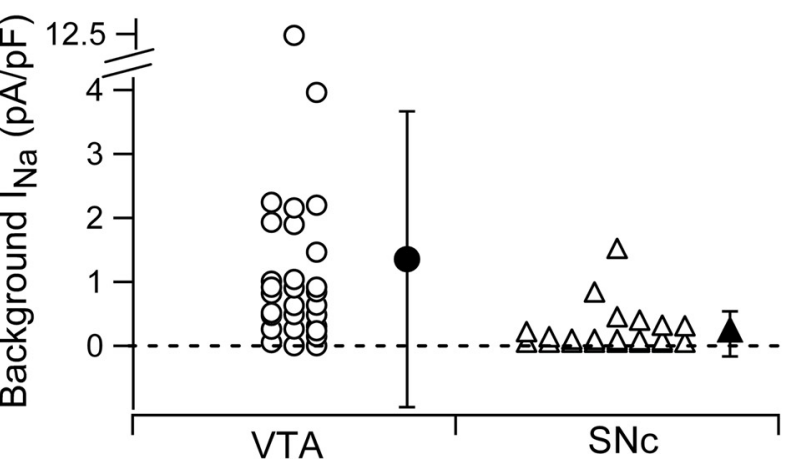

Figure 10. Comparison of background sodium leak current in SNc and VTA neurons. Voltage dependence of background sodium urrents before (black) and after (red) replacement of external sodium by NMDG (both solutions containing TTX). B, Ramp-evoked mV, likely corresponding to voltage-activated calcium current. C, Collected results of background sodium current measured at $-85 \mathrm{mV}$ from 29 VTA neurons and $21 \mathrm{SNc}$ neurons.

sodium current is in striking contrast with SNc neurons, where voltage-dependent calcium current is much larger than TTXsensitive sodium current at subthreshold voltages (Puopolo et al., 2007). These differences in voltage clamp are consistent with the differences between VTA and SNc neurons in current clamp, with pacemaking in VTA neurons continuing when calcium is replaced by magnesium and with lack of calcium-dependent oscillations (in most cells) in the presence of TTX.

A second difference is that most $\mathrm{SNc}$ neurons have little or no background sodium leak current (as assayed by NMDG replacement for sodium with TTX present). This difference was striking because the experiments were done using exactly the same solutions and protocols as for VTA neurons. On average, the current density of background sodium current in SNc neurons was only $\sim 15 \%$ of that in VTA neurons, and many SNc neurons had none at all. Interestingly, there is a reciprocal relationship for the density of $I_{\mathrm{h}}$, which is typically much larger in SNc neurons than in VTA neurons (Neuhoff et al., 2002). It is possible that in $\mathrm{SNc}$ neurons the depolarized resting potential (relative to the potassium equilibrium potential) results partly from the sodium permeability of resting $I_{\mathrm{h}}$ currents, which in other types of neurons can help set resting potential (Doan and Kunze, 1999; Day et al., 2005; Aponte et al., 2006; Meuth et al., 
2006), while in VTA neurons the resting sodium permeability is mainly from a different, non-voltage-dependent background sodium conductance.

\section{Comparison with other pacemaking central neurons}

The mechanism of pacemaking in VTA neurons seems very similar to that in a number of other neuronal types in which pacemaking depends primarily on subthreshold TTX-sensitive "persistent" sodium current, including suprachiasmatic nucleus neurons (Pennartz et al., 1997; Jackson et al., 2004), striatal cholinergic interneurons (Bennett et al., 2000), and tuberomammillary neurons (Uteshev et al., 1995; Taddese and Bean, 2002). In these neurons, there is a steady-state TTX-sensitive sodium current that begins to activate near $-60 \mathrm{mV}$ and is steeply voltage dependent, with a midpoint near $-55 \mathrm{mV}$ and maximum current near $-45 \mathrm{mV}$. This current can produce spontaneous depolarization from approximately $-60 \mathrm{mV}$ to spike threshold. A key element for pacemaking in such neurons is a resting potential that is positive to $-60 \mathrm{mV}$ (measured when spontaneously activity is stopped by TTX), where the voltage-dependent persistent sodium current can be engaged. Thus, after a spike, the conductances responsible for the resting potential bring the membrane potential positive to $-60 \mathrm{mV}$, where the TTX-sensitive steadystate current is activated and brings the membrane potential to spike threshold. In all these examples, pacemaking can occur without requiring $I_{\mathrm{h}}$ or (when tested) subthreshold calcium currents. In the case of spontaneously active deep cerebellar nuclei neurons, TTX-sensitive steady-state current is present at subthreshold voltages but is not strictly required to reach threshold because the resting potential in TTX is itself depolarized relative to spike threshold (Raman et al., 2000); GABAergic substantia nigra pars reticulata neurons (Atherton and Bevan, 2005) and orexinergic hypothalamic neurons (Eggermann et al., 2003) behave similarly.

\section{Resting membrane potential}

In all these cases, a key element in pacemaking is a resting potential positive to $-60 \mathrm{mV}$, very depolarized compared to the potassium equilibrium potential near $-95 \mathrm{mV}$. In fact, the resting potentials of virtually all neurons are significantly depolarized to the potassium equilibrium potential, although often to a lesser degree. The resting potassium conductance of neurons appears to be due to two-pore-domain potassium channels (Goldstein et al., 2001; Talley et al., 2003; Honoré, 2007), which are nearly perfectly potassium selective and reverse near the potassium equilibrium potential. The high selectivity for potassium of these channels suggests that neurons possess additional background channels with significant permeability to sodium ions. Three conductances are known to produce resting permeability to sodium ions in various types of neurons: $I_{\mathrm{h}}$ channels, TTX-sensitive sodium channels, and a newly described "NALCN" channel (Lu et al., 2007). The NALCN channel is a plausible candidate for the TTX-insensitive background sodium conductance in VTA neurons. Using cultured VTA neurons, Lu et al. (2009) showed that the NALCN channel appears to underlie a nonselective cation current activated by neurotensin or substance P. However, it remains unclear whether the channels are open basally in VTA cells, either in culture or in acute brain slices.

\section{Accuracy of resting potential measurements}

Accurate measurements of resting potential are clearly critical to understanding pacemaking. In our experiments, the average membrane potential measured noninvasively using the reversal potential of potassium currents in cell-attached patches $(-57 \pm$ $8 \mathrm{mV}$ ) was essentially identical to the resting potential measured with conventional whole-cell recordings $(-56 \pm 5 \mathrm{mV})$. Our results support the idea that the measurement of the reversal of patch potassium currents can give a highly accurate estimate of resting potential and can be used to accurately define changes in membrane potential produced by ionic changes (Verheugen et al., 1995, 1999; Fricker et al., 1999). Besides the advantage of not requiring dialysis of the cell, a major advantage of the "patch potassium reversal" technique is that true changes in membrane potential produced by ionic changes such as replacing sodium by NMDG can be distinguished from possible effects of these manipulations on seal resistance, since changes in seal resistance are taken into account when measuring the reversal potential of the voltage-activated potassium currents in the patch. In fact, however, we saw no significant effect on seal resistance when replacing sodium by NMDG, and the hyperpolarization resulting from this replacement was nearly identical in whole-cell $(-11 \pm 8 \mathrm{mV})$ and cell-attached patch $(-13 \pm 7 \mathrm{mV})$ experiments, suggesting that it represents a true change in membrane potential reflecting a significant resting permeability to sodium.

\section{Electrophysiological differences among midbrain dopamine neuron subpopulations}

There is increasing evidence that although midbrain dopamine neurons projecting to different brain regions are broadly similar in some basic electrophysiological properties such as pacemaking and having broad action potentials, there are considerable differences in the ionic conductances expressed by subpopulations of the neurons [for review, see Korotkova et al. (2004) and Liss and Roeper (2008)]. Compared to SNc neurons, VTA neurons have smaller SK Ca-activated potassium currents (Wolfart et. Al., 2001) and smaller $I_{\mathrm{h}}$ currents (Neuhoff et al., 2002), and a subpopulation of VTA neurons projecting to prefrontal cortex are notable for having minimal activation of GIRK channels by $\mathrm{D}_{2}$ receptors (Chiodo et al., 1984; Lammel et al., 2008). Our results show a qualitative difference in the mechanism of pacemaking in VTA neurons compared to SNc neurons in that there is little role of subthreshold calcium current in driving pacemaking in VTA neurons, in striking contrast to the prominent role of calcium current in pacemaking of SNc neurons (Fujimura and Matsuda, 1989; Grace and Onn, 1989; Harris et al., 1989; Kang and Kitai, 1993a,b; Wilson and Callaway, 2000; Chan et al., 2007; Puopolo et al., 2007; Putzier et al., 2009). The much larger subthreshold calcium current in SNc neurons compared to VTA neurons supports the hypothesis of Chan et al. (2007) that SNc neurons may be selectively vulnerable to cell death in Parkinson's disease because more calcium enters during pacemaking.

\section{References}

Anderson D, Mehaffey WH, Iftinca M, Rehak R, Engbers JD, Hameed S, Zamponi GW, Turner RW (2010) Regulation of neuronal activity by Cav3-Kv4 channel signaling complexes. Nat Neurosci 13:333-337.

Aponte Y, Lien CC, Reisinger E, Jonas P (2006) Hyperpolarizationactivated cation channels in fast-spiking interneurons of rat hippocampus. J Physiol 574:229-243.

Astman N, Gutnick MJ, Fleidervish IA (2006) Persistent sodium current in layer 5 neocortical neurons is primarily generated in the proximal axon. J Neurosci 26:3465-3473.

Atherton JF, Bevan MD (2005) Ionic mechanisms underlying autonomous action potential generation in the somata and dendrites of GABAergic substantia nigra pars reticulata neurons in vitro. J Neurosci 25: $8272-8281$

Atherton JF, Wokosin DL, Ramanathan S, Bevan MD (2008) Autonomous 
initiation and propagation of action potentials in neurons of the subthalamic nucleus. J Physiol 586:5679-5700.

Bennett BD, Callaway JC, Wilson CJ (2000) Intrinsic membrane properties underlying spontaneous tonic firing in neostriatal cholinergic interneurons. J Neurosci 20:8493-8503.

Bevan MD, Wilson CJ (1999) Mechanisms underlying spontaneous oscillation and rhythmic firing in rat subthalamic neurons. J Neurosci 19:7617-7628.

Breton JD, Stuart GJ (2009) Loss of sensory input increases the intrinsic excitability of layer 5 pyramidal neurons in rat barrel cortex. J Physiol 587:5107-5119.

Brickley SG, Aller MI, Sandu C, Veale EL, Alder FG, Sambi H, Mathie A, Wisden W (2007) TASK-3 two-pore domain potassium channels enable sustained high-frequency firing in cerebellar granule neurons. J Neurosci 27:9329-9340.

Cameron DL, Wessendorf MW, Williams JT (1997) A subset of ventral tegmental area neurons is inhibited by dopamine, 5 -hydroxytryptamine and opioids. Neuroscience 77:155-166.

Chan CS, Guzman JN, Ilijic E, Mercer JN, Rick C, Tkatch T, Meredith GE, Surmeier DJ (2007) 'Rejuvenation' protects neurons in mouse models of Parkinson's disease. Nature 447:1081-1086.

Chan CS, Gertler TS, Surmeier DJ (2009) Calcium homeostasis, selective vulnerability and Parkinson's disease. Trends Neurosci 32:249-256.

Chiodo LA, Bannon MJ, Grace AA, Roth RH, Bunney BS (1984) Evidence for the absence of impulse-regulating somatodendritic and synthesismodulating nerve terminal autoreceptors on subpopulations of mesocortical dopamine neurons. Neuroscience 12:1-16.

Dauer W, Przedborski S (2003) Parkinson's disease: mechanisms and models. Neuron 39:889-909.

Day M, Carr DB, Ulrich S, Ilijic E, Tkatch T, Surmeier DJ (2005) Dendritic excitability of mouse frontal cortex pyramidal neurons is shaped by the interaction among $\mathrm{HCN}$, Kir2, and $\mathrm{K}_{\text {leak }}$ channels. J Neurosci 25:8776-8787.

Doan TN, Kunze DL (1999) Contribution of the hyperpolarizationactivated current to the resting membrane potential of rat nodose sensory neurons. J Physiol 514:125-138.

Eggermann E, Bayer L, Serafin M, Saint-Mleux B, Bernheim L, Machard D, Jones BE, Mühlethaler M (2003) The wake-promoting hypocretinorexin neurons are in an intrinsic state of membrane depolarization. J Neurosci 23:1557-1562.

Fields HL, Hjelmstad GO, Margolis EB, Nicola SM (2007) Ventral tegmental area neurons in learned appetitive behavior and positive reinforcement. Annu Rev Neurosci 30:289-316.

Ford CP, Mark GP, Williams JT (2006) Properties and opioid inhibition of mesolimbic dopamine neurons vary according to target location. J Neurosci 26:2788-2797.

Fricker D, Verheugen JA, Miles R (1999) Cell-attached measurements of the firing threshold of rat hippocampal neurones. J Physiol 517:791-804.

Fujimura K, Matsuda Y (1989) Autogenous oscillatory potentials in neurons of the guinea pig substantia nigra pars compacta in vitro. Neurosci Lett 104:53-57.

Goldstein SA, Bockenhauer D, O'Kelly I, Zilberberg N (2001) Potassium leak channels and the KCNK family of two-P-domain subunits. Nat Rev Neurosci 2:175-184.

Gong S, Zheng C, Doughty ML, Losos K, Didkovsky N, Schambra UB, Nowak NJ, Joyner A, Leblanc G, Hatten ME, Heintz N (2003) A gene expression atlas of the central nervous system based on bacterial artificial chromosomes. Nature 425:917-925.

Grace AA, Bunney BS (1984) The control of firing pattern in nigral dopamine neurons: single spike firing. J Neurosci 4:2866-2876.

Grace AA, Onn SP (1989) Morphology and electrophysiological properties of immunocytochemically identified rat dopamine neurons recorded in vitro. J Neurosci 9:3463-3481.

Guzman JN, Sánchez-Padilla J, Chan CS, Surmeier DJ (2009) Robust pacemaking in substantia nigra dopaminergic neurons. J Neurosci 29:11011-11019.

Harris NC, Webb C, Greenfield SA (1989) A possible pacemaker mechanism in pars compacta neurons of the guinea-pig substantia nigra revealed by various ion channel blocking agents. Neuroscience 31:355-362.

Hille B, Woodhull AM, Shapiro BI (1975) Negative surface charge near sodium channels of nerve: divalent ions, monovalent ions, and $\mathrm{pH}$. Philos Trans R Soc Lond B Biol Sci 270:301-318.
Hodgkin AL, Huxley AF (1952) A quantitative description of membrane current and its application to conduction and excitation in nerve. J Physiol 117:500-544.

HonoréE (2007) The neuronal background K2P channels: focus on TREK1. Nat Rev Neurosci 8:251-261.

Jackson AC, Yao GL, Bean BP (2004) Mechanism of spontaneous firing in dorsomedial suprachiasmatic nucleus neurons. J Neurosci 24:7985-7998.

Johnson SW, North RA (1992) Two types of neurone in the rat ventral tegmental area and their synaptic inputs. J Physiol 450:455-468.

Kaczorowski CC, Disterhoft J, Spruston N (2007) Stability and plasticity of intrinsic membrane properties in hippocampal CA1 pyramidal neurons: effects of internal anions. J Physiol 578:799-818.

Kang Y, Kitai ST (1993a) Calcium spike underlying rhythmic firing in dopaminergic neurons of the rat substantia nigra. Neurosci Res 18:195-207.

Kang Y, Kitai ST (1993b) A whole cell patch-clamp study on the pacemaker potential in dopaminergic neurons of rat substantia nigra compacta. Neurosci Res 18:209-221.

Khaliq ZM, Bean BP (2008) Dynamic, nonlinear feedback regulation of slow pacemaking by A-type potassium current in ventral tegmental area neurons. J Neurosci 28:10905-10917.

Korotkova TM, Sergeeva OA, Eriksson KS, Haas HL, Brown RE (2003) Excitation of ventral tegmental area dopaminergic and nondopaminergic neurons by orexins/hypocretins. J Neurosci 23:7-11.

Korotkova TM, Ponomarenko AA, Brown RE, Haas HL (2004) Functional diversity of ventral midbrain dopamine and GABAergic neurons. Mol Neurobiol 29:243-259.

Koyama S, Appel SB (2006) A-type K+ current of dopamine and GABA neurons in the ventral tegmental area. J Neurophysiol 96:544-554.

Koyama S, Kanemitsu Y, Weight FF (2005) Spontaneous activity and properties of two types of principal neurons from the ventral tegmental area of rat. J Neurophysiol 93:3282-3293.

Lammel S, Hetzel A, Häckel O, Jones I, Liss B, Roeper J (2008) Unique properties of mesoprefrontal neurons within a dual mesocorticolimbic dopamine system. Neuron 57:760-773.

Liss B, Roeper J (2008) Individual dopamine midbrain neurons: functional diversity and flexibility in health and disease. Brain Res Rev 58:314-321.

Llinás R, Sugimori M, Simon SM (1982) Transmission by presynaptic spike-like depolarization in the squid giant synapse. Proc Natl Acad Sci U S A 79:2415-2419.

Lu B, Su Y, Das S, Liu J, Xia J, Ren D (2007) The neuronal channel NALCN contributes resting sodium permeability and is required for normal respiratory rhythm. Cell 129:371-383.

Lu B, Su Y, Das S, Wang H, Wang Y, Liu J, Ren D (2009) Peptide neurotransmitters activate a cation channel complex of NALCN and UNC-80. Nature 457:741-744.

Margolis EB, Lock H, Hjelmstad GO, Fields HL (2006) The ventral tegmental area revisited: is there an electrophysiological marker for dopaminergic neurons? J Physiol 577:907-924.

Margolis EB, Mitchell JM, Ishikawa J, Hjelmstad GO, Fields HL (2008) Midbrain dopamine neurons: projection target determines action potential duration and dopamine $\mathrm{D}_{2}$ receptor inhibition. J Neurosci 28:89088913.

Mercuri NB, Bonci A, Calabresi P, Stratta F, Stefani A, Bernardi G (1994) Effects of dihydropyridine calcium antagonists on rat midbrain dopaminergic neurones. Br J Pharmacol 113:831-838.

Meuth SG, Kanyshkova T, Meuth P, Landgraf P, Munsch T, Ludwig A, Hofmann F, Pape HC, Budde T (2006) Membrane resting potential of thalamocortical relay neurons is shaped by the interaction among TASK 3 and HCN2 channels. J Neurophysiol 96:1517-1529.

Mosharov EV, Larsen KE, Kanter E, Phillips KA, Wilson K, Schmitz Y, Krantz DE, Kobayashi K, Edwards RH, Sulzer D (2009) Interplay between cytosolic dopamine, calcium, and $\alpha$-synuclein causes selective death of substantia nigra neurons. Neuron 62:218-229.

Nedergaard S, Greenfield SA (1992) Sub-populations of pars compacta neurons in the substantia nigra: the significance of qualitatively and quantitatively distinct conductances. Neuroscience 48:423-437.

Nedergaard S, Flatman JA, Engberg I (1993) Nifedipine- and omegaconotoxin-sensitive $\mathrm{Ca} 2+$ conductances in guinea-pig substantia nigra pars compacta neurones. J Physiol 466:727-747.

Neher E (1992) Correction for liquid junction potentials in patch clamp experiments. Methods Enzymol 207:123-131.

Neuhoff H, Neu A, Liss B, Roeper J (2002) $I_{\mathrm{h}}$ channels contribute to the 
different functional properties of identified dopaminergic subpopulations in the midbrain. J Neurosci 22:1290-1302.

Nieoullon A (2002) Dopamine and the regulation of cognition and attention. Prog Neurobiol 67:53-83.

Pennartz CM, Bierlaagh MA, Geurtsen AM (1997) Cellular mechanisms underlying spontaneous firing in rat suprachiasmatic nucleus: involvement of a slowly inactivating component of sodium current. J Neurophysiol 78:1811-1825.

Puopolo M, Raviola E, Bean BP (2007) Roles of subthreshold calcium current and sodium current in spontaneous firing of mouse midbrain dopamine neurons. J Neurosci 27:645-656.

Putzier I, Kullmann PH, Horn JP, Levitan ES (2009) Cav1.3 channel voltage dependence, not $\mathrm{Ca}^{2+}$ selectivity, drives pacemaker activity and amplifies bursts in nigral dopamine neurons. J Neurosci 29:15414-15419.

Raman IM, Gustafson AE, Padgett D (2000) Ionic currents and spontaneous firing in neurons isolated from the cerebellar nuclei. J Neurosci 20:9004-9016.

Schultz W (2007) Multiple dopamine functions at different time courses. Annu Rev Neurosci 30:259-288.

Seutin V, Massotte L, Renette MF, Dresse A (2001) Evidence for a modulatory role of Ih on the firing of a subgroup of midbrain dopamine neurons. Neuroreport 12:255-258.

Surmeier DJ (2007) Calcium, ageing, and neuronal vulnerability in Parkinson's disease. Lancet Neuron 6:933-938.

Taddese A, Bean BP (2002) Subthreshold sodium current from rapidly in- activating sodium channels drives spontaneous firing of tuberomammillary neurons. Neuron 33:587-600.

Takakusaki K, Kitai ST (1997) Ionic mechanisms involved in the spontaneous firing of tegmental pedunculopontine nucleus neurons of the rat Neuroscience 78:771-794.

Talley EM, Sirois JE, Lei Q, Bayliss DA (2003) Two-pore-Domain (KCNK) potassium channels: dynamic roles in neuronal function. Neuroscientis 9:46-56.

Uteshev V, Stevens DR, Haas HL (1995) A persistent sodium current in acutely isolated histaminergic neurons from rat hypothalamus. Neuroscience 66:143-149.

Verheugen JA, Vijverberg HP, Oortgiesen M, Cahalan MD (1995) Voltagegated and $\mathrm{Ca}(2+)$-activated $\mathrm{K}+$ channels in intact human $\mathrm{T}$ lymphocytes. Noninvasive measurements of membrane currents, membrane potential, and intracellular calcium. J Gen Physiol 105:765-794.

Verheugen JA, Fricker D, Miles R (1999) Noninvasive measurements of the membrane potential and GABAergic action in hippocampal interneurons. J Neurosci 19:2546-2555.

Wilson CJ, Callaway JC (2000) Coupled oscillator model of the dopaminergic neuron of the substantia nigra. J Neurophysiol 83:3084-3100.

Wise RA (2004) Dopamine, learning and motivation. Nat Rev Neurosci 5:483-494.

Wolfart J, Neuhoff H, Franz O, Roeper J (2001) Differential expression of the small-conductance, calcium-activated potassium channel SK3 is critical for pacemaker control in dopaminergic midbrain neurons. J Neurosci 21:3443-3456. 